\title{
Ictal blinking, an under-recognized phenomenon: our experience and literature review
}

\author{
This article was published in the following Dove Press journal: \\ Neuropsychiatric Disease and Treatment \\ 31 May 2017 \\ Number of times this article has been viewed
}

\author{
Marco Andrea Nicola \\ Saporito' \\ Giovanna Vitaliti² \\ Piero Pavone ${ }^{2}$ \\ Giuseppa Di Stefano' \\ Pasquale Striano ${ }^{3}$ \\ Roberto Horacio \\ Caraballo 4 \\ Raffaele Falsaperla ${ }^{2}$
}

'Neonatal Intensive Care Unit, Santo Bambino Hospital, Policlinico-Vittorio Emanuele University Hospital, University of Catania, Catania, Italy; ${ }^{2}$ Paediatric Operative Unit and Acute and Emergency, Policlinico-Vittorio Emanuele University Hospital, University of Catania, Catania, Italy; ${ }^{3}$ Pediatric Neurology and Muscular Diseases Unit, Department of Neurosciences, Rehabilitation, Ophtalmology, Genetics, Maternal and Child Health, Institute "G. Gaslini” University of Genova, Genoa, Italy; ${ }^{4}$ Department of Neurology, Hospital de Pediatría "Prof Dr Juan P Garrahan”, Buenos Aires, Argentina

Correspondence: Marco Andrea Nicola Saporito

Neonatal Intensive Care Unit, Santo Bambino Hospital, Vittorio-Emanuele University Hospital, University of Catania, Via Tindaro 2, 95I24 Catania, Italy

Tel +390957435532

Fax +390957435562

Email marcosaporito@hotmail.com

\begin{abstract}
Ictal blinking (IB) is a very rare disease manifesting as an epileptic motor event in children and adults. Until now it has not been included in any classification of focal seizures of the International League Against Epilepsy Commission. It could be unilateral or bilateral, isolated or in association with other motor manifestations such as limbs' clonus and spasms. Its pathogenesis has not been clearly established: paroxysmal discharges from different areas of the brain could cause IB by activation of trigeminal fibers. Herein authors report three infants and a child with IB, observed in three pediatric centers in two different countries. We also performed a review of literature data, suggesting IB as a seizure type to be included in international classifications, and describing the specific electroencephalographic pattern of this condition.
\end{abstract}

Keywords: ictal blinking, focal motor phenomenon, ictal electroencephalographic pattern, occipital area, infancy

\section{Introduction}

Ictal blinking (IB) is a smooth blinking of the eyes not associated with other facial spasms, secondary to a paroxysmal epileptic discharge. ${ }^{1}$ It was first described in 1874 by Bartholow in a female volunteer after stimulation of the ipsilateral posterior lobe. ${ }^{2}$ This condition could present as unilateral or bilateral blinking, isolated or associated with other motor manifestations. When unilateral, it mostly involves the left side, representing a rare lateralizing sign of partial seizures. ${ }^{3}$ Literature data estimated frequency of the condition of approximately $0.8 \%-1.5 \%$ of children and adults with a positive predictive value of $83 \% .^{1,4}$ The isolated form is a very rare event; in fact, in the literature only two cases have been described in infancy. ${ }^{5,6}$ Its pathogenesis has not yet been clearly established. IB may represent an expression of many diseases of the central nervous system (CNS), such as epilepsy, stroke, and Parkinson's disease. . $^{3,5}$ In this regard, the International League Against Epilepsy (ILAE) Commission has not yet included IB in the focal motor seizure group, ${ }^{7,8}$ because there is not an electroencephalographic univocal pattern and ictal electroencephalographic pattern could be covered by other paroxysmal discharges.

Herein, authors report their experience in cases of IB and perform a review of literature data, suggesting IB as a seizure type to be included in international classifications, and describing the specific electroencephalographic pattern of this condition.

\section{Case descriptions}

Herein, we describe three infants and a child with IB, three observed in two pediatric centers in Italy, and one observed in a center in Argentina, from 2014 to 2016 (Table 1), one female and three males. The median age at onset was 12.5 months of life (with a 
Table I Electroclinical data of the patients

\begin{tabular}{|c|c|c|c|c|c|c|c|}
\hline Patient & Sex & $\begin{array}{l}\text { Age at } \\
\text { diagnosis } \\
\text { (months) }\end{array}$ & $\begin{array}{l}\text { Blinking } \\
\text { localization }\end{array}$ & $\begin{array}{l}\text { Other motor } \\
\text { manifestations }\end{array}$ & $\begin{array}{l}\text { Interictal and ictal EEG } \\
\text { findings }\end{array}$ & Brain MRI & Diagnosis \\
\hline I & $\mathrm{F}$ & 5 & Right & $\begin{array}{l}\text { Neck and limb } \\
\text { flexion spasms }\end{array}$ & $\begin{array}{l}\text { Hypsarrhythmia; rapid right } \\
\text { occipital activity }\end{array}$ & $\begin{array}{l}\text { Large cyst in right } \\
\text { trigonal region }\end{array}$ & $\begin{array}{l}\text { Symptomatic } \\
\text { infantile spasms }\end{array}$ \\
\hline 2 & $M$ & 3 & Left & No & $\begin{array}{l}\text { Hemi-hypsarrhythmia; } \\
\text { left occipital slow wave } \\
\text { complexes and super- } \\
\text { imposed fast activity } \\
\text { followed by voltage decrease }\end{array}$ & $\begin{array}{l}\text { Left cortical and } \\
\text { subcortical porencephaly }\end{array}$ & $\begin{array}{l}\text { Symptomatic focal } \\
\text { epilepsy }\end{array}$ \\
\hline 3 & $M$ & 36 & Right & $\begin{array}{l}\text { Left-side } \\
\text { hemilateral seizures }\end{array}$ & $\begin{array}{l}\text { Slowed background; right } \\
\text { occipital high voltage spike- } \\
\text { wave complexes }\end{array}$ & $\begin{array}{l}\text { Right focal cortical } \\
\text { dysplasia }\end{array}$ & $\begin{array}{l}\text { Symptomatic focal } \\
\text { epilepsy }\end{array}$ \\
\hline 4 & $M$ & 6 & Right & $\begin{array}{l}\text { Right-side clonic } \\
\text { jerks }\end{array}$ & $\begin{array}{l}\text { Left occipital slow waves and } \\
\text { spikes; left occipital irregular } \\
\text { slow theta activity followed } \\
\text { by diffuse slow waves with } \\
\text { superimposed fast rhythms }\end{array}$ & $\begin{array}{l}\text { Left parieto-occipital } \\
\text { focal cortical dysplasia }\end{array}$ & $\begin{array}{l}\text { Symptomatic focal } \\
\text { epilepsy }\end{array}$ \\
\hline
\end{tabular}

Abbreviations: EEG, electroencephalography; F, female; M, male; MRI, magnetic resonance imaging.

range between 3-36 months). In three cases the right eye was involved, in one the left eye.

The physical examination was normal in all patients. Their neurological examination showed the presence of developmental delay. All studied patients underwent continuous video-electroencephalography (EEG) monitoring, with interictal and ictal EEG recording; it was not possible to use oculi electrodes because of the young age of the patients. In one case IB was the only clinical manifestation, ${ }^{5}$ while in the others it was associated with limbs' clonus and tonic spasms.

\section{Case one}

A 6-month-old female infant with West syndrome, defined as "combination of spasms that occur in clusters and hypsarrhythmia on an EEG", ${ }^{9}$ was admitted to the General Pediatrics and Pediatric Emergency Operative Unit of the University of Catania, for the onset, from 1 month, of neck and limb spasms in flection, associated with IB, involving her right eye. The episodes were isolated and accidental.

Her anamnesis was positive for a large cyst found at birth in her trigonal region, for which she underwent a neurosurgical intervention of cyst emptying.

Her brain magnetic resonance imaging (MRI) showed the reappearance of the cyst in her right trigonal region. Interictal EEG demonstrated hypsarrhythmia, while ictal EEG showed a rapid activity arising from the right occipital area. The child, therefore, underwent a protocol treatment with pyridoxine and pyridoxal phosphate for 9 days and high dosage of methylprednisolone for 14 days with gradual resolution of clinical seizures; afterwards sodium valproate was started with a good control of symptoms. The infant was then admitted to the Neurosurgical Unit for further evaluation of the cyst.

\section{Case two}

A 6-month-old male infant, born at full term to unrelated parents after a pregnancy complicated by hypertension during the third trimester, was admitted to the General Pediatrics and Pediatric Emergency Operative Unit of the University of Catania, for the onset of IB when he was 3 months old, involving his left eye, representing the only clinical manifestation. His consciousness was intact during the episodes.

Brain MRI revealed cortical and subcortical porencephalic hollows of the left hemisphere. His interictal EEG showed slow background activity, high voltage spikes, and spike-wave complexes over his left occipital areas. The ictal EEG revealed a focal pattern arising from the left occipital lesion, characterized by slow wave complexes and superimposed fast activity followed by voltage decrease. Treatment with sodium valproate was started with resolution of IB, but persistence of right partial seizures. This case was previously described in detail. ${ }^{5}$

\section{Case three}

A 5-year-old boy born at full term to healthy parents and affected by symptomatic, drug-resistant, focal epilepsy from the age of 36 months with right IB episodes, sometimes followed by left hemilateral seizures, was admitted to the Pediatric Neurology 
and Muscular Diseases Unit of "G. Gaslini” Institute of the University of Genova. His EEG study revealed diffused slow background and right occipital high voltage spike-wave complexes followed by voltage decrement.

His brain MRI showed the presence of right focal cortical dysplasia. He did not respond to several trials of anticonvulsant drugs (carbamazepine, sodium valproate, phenobarbital, clobazam) and became seizure-free only after surgery.

\section{Case four}

A 30-month-old boy without personal and familial antecedent, with unilateral right eye blinking as a single ictal manifestation without other facial motor manifestation, was admitted to the Pediatric Hospital "JP Garrahan" in Buenos Aires. The clinical onset of this ictal event was first recorded at 6 months of age. His eye blinking increased progressively until it became a daily occurrence at 8 months of age. During these episodes, the infant showed intact consciousness, and occasionally the blinking episodes were associated with clonic jerks in the right hemibody. The episodes presented in a cluster.

A video-EEG documented a focal pattern characterized by irregular slow theta activity arising from the left occipital region followed by diffuse slow waves with superimposed fast rhythms. His interictal EEG recording showed slow waves and spikes in his left occipital region.

Brain MRI showed the presence of focal cortical dysplasia in his left parieto-occipital region. The patient presented with developmental delay.

As far as therapy was concerned, the boy was refractory to carbamazepine and sodium valproate. Vigabatrin was then introduced, followed by a significant reduction in seizures.

At follow-up control, the patient continued to have sporadic right hemibody motor focal seizures associated with parieto-occipital spikes. He had isolated eye blinking.

\section{Discussion}

IB is caused by activation of trigeminal fibers during seizures: Sindou et $\mathrm{al}^{10}$ showed that direct intracranial stimulation of trigeminal fibers determined ipsilateral blinking, while Aramideh and Ongerboer de Visser demonstrated that extracranial stimulation of trigeminal fibers caused a blink reflex. ${ }^{11}$ It has been suggested that the ipsilateral precentral cortex could be involved in IB. ${ }^{3}$ The pathogenetic pathways are not well understood; many mechanisms have been suggested: stimulation of ipsilateral cerebellum, frontal and basal region of the temporal lobe, occipital area and basal hemisphere structures could be involved..$^{5,6}$
In the literature, few cases of unilateral IB (UIB) have been described in infants, and it is often associated with other motor activity. An isolated case of IB in an infant was described in 2007 by Pestana and Gupta, ${ }^{6}$ in a 3-monthold identical twin infant born at 29 weeks gestation with periventricular leukomalacia, encephalomalacia in the left frontal region, and a history of ventricular-peritoneal shunt placement for tetraventricular hydrocephalus due to intraventricular hemorrhage with partial seizures, involving the child's homolateral frontotemporal region; the authors found an ictal EEG showing repetitive sharp waves in the left frontal and temporal region. In our studied patients, IB was an isolated manifestation in one case - the case published in 2016 by Falsaperla et al. ${ }^{5}$

In 1996, Benbadis et al described 14 patients, from 18 months to 50 years, with UIB, homolateral to the lesion in ten of them, showing that UIB could be a reliable lateralizing sign. ${ }^{1}$ On the contrary, in 2016, Jadhav et al described UIB in eleven children with tuberous sclerosis complex, and noted that it was not a reliable lateralizing sign. The authors described that when UIB was early in seizures, lateralization was more often contralateral. ${ }^{12}$

In 2002, Mesiwala et al described a case of an infant with a cerebellar ganglioma associated with ipsilateral blinking; ${ }^{13}$ the authors found an ictal EEG pattern characterized by fast activity over the left frontal/frontopolar region. An intraoperative deep EEG showed paroxysmal discharges raised within the cerebellar lesion and then cortical hemispheres.

In 2012, Specchio et al reported two cases of infants with a fourth ventricle mass who presented with bilateral blinking associated with hemifacial spasm predominantly ipsilateral to the lesion, and occasionally tachypnea and ipsilateral eye deviation, with no epileptic discharge at ictal EEG. ${ }^{14}$

In 2013, Kalss et $\mathrm{al}^{3}$ described two adults with drugresistant focal epilepsy and blinking - at the beginning bilateral and then unilateral, suggesting a cortical blink inhibition of the contralateral eye caused by seizures in the frontotemporal region; in fact during ictal EEG recording they noted changes in EEG pattern after switching from bilateral to unilateral eye blinking: from rhythmic sharp waves over both frontotemporal areas, to decreased sharp waves in the two frontal regions and over the temporal region with predominantly documented sharp waves over the right temporal region.

In Table 2 we reported the cases of IB in infants reported in the literature. In our cohort, ictal EEG showed a rapid wave activity that precedes blinking in three cases, and in one case, the Argentinian one, irregular slow theta activity. 
Table 2 Cases of ictal blinking in infants reported in the literature

\begin{tabular}{|c|c|c|c|c|c|c|}
\hline $\begin{array}{l}\text { Author } \\
\text { and year }\end{array}$ & $\begin{array}{l}\text { Sex/age } \\
\text { (months) }\end{array}$ & $\begin{array}{l}\text { Blinking } \\
\text { localization }\end{array}$ & $\begin{array}{l}\text { Other motor } \\
\text { manifestations }\end{array}$ & $\begin{array}{l}\text { Seizure } \\
\text { frequency }\end{array}$ & Ictal EEG & Brain MRI \\
\hline $\begin{array}{l}\text { Pestana and } \\
\text { Gupta, } 2007^{6}\end{array}$ & $M / 3$ & Left & $\begin{array}{l}\text { High-pitched cry, flushing, } \\
\text { sweating, and stiffening of } \\
\text { the whole body }\end{array}$ & Multiple daily & $\begin{array}{l}\text { Repetitive sharp waves in } \\
\text { left frontal and temporal } \\
\text { region }\end{array}$ & $\begin{array}{l}\text { Hydrocephalus with a } \\
\text { VPS tract and surrounding } \\
\text { encephalomalacia in left } \\
\text { frontal region }\end{array}$ \\
\hline $\begin{array}{l}\text { Mesiwala } \\
\text { et al, } 2002^{13}\end{array}$ & $M /$ first days & Left & $\begin{array}{l}\text { Postural arching, } \\
\text { extremity twitching, } \\
\text { limb rowing movement, } \\
\text { chewing and pursed lips }\end{array}$ & Multiple daily & & Left cerebellar ganglioma \\
\hline $\begin{array}{l}\text { Specchio } \\
\text { et al, } 2012^{14}\end{array}$ & $\mathrm{~F} / \mathrm{IO}$ & Bilateral & $\begin{array}{l}\text { Hemifacial spasm } \\
\text { ipsilateral to the lesion }\end{array}$ & Clusters & No epileptiform discharges & $\begin{array}{l}\text { Left side of the floor of } \\
\text { the fourth ventricle mass } \\
\text { involving the left middle } \\
\text { cerebellar peduncle }\end{array}$ \\
\hline $\begin{array}{l}\text { Specchio } \\
\text { et al, } 2012^{14}\end{array}$ & $M / 9$ & Bilateral & $\begin{array}{l}\text { Hemifacial spasm } \\
\text { ipsilateral to the lesion }\end{array}$ & Clusters & No epileptiform discharges & $\begin{array}{l}\text { Right side of the floor of } \\
\text { the fourth ventricle mass } \\
\text { involving the right cerebellar } \\
\text { hemisphere and the adjacent } \\
\text { middle cerebellar peduncle }\end{array}$ \\
\hline
\end{tabular}

Abbreviations: EEG, electroencephalography; F, female; M, male; MRI, magnetic resonance imaging; VPS, ventricular-peritoneal shunt.

This focal pattern started from the occipital area homolateral to IB in three cases, contralateral to IB in one case, and it is followed by slow wave complex and superimposed fast activity (Figure 1). This diffuse EEG paroxysm could be an EEG manifestation of epileptic spasms, even if we were not able to demonstrate its relationship with those spasms.
This ictal electroencephalographic pattern has never been described before in the literature. Another aspect in favor of EEG is that the episodes were clustered and one of them showed hypsarrhythmia.

Continuous and ictal video-EEG is crucial for an appropriate diagnosis of IB and for recognition of a

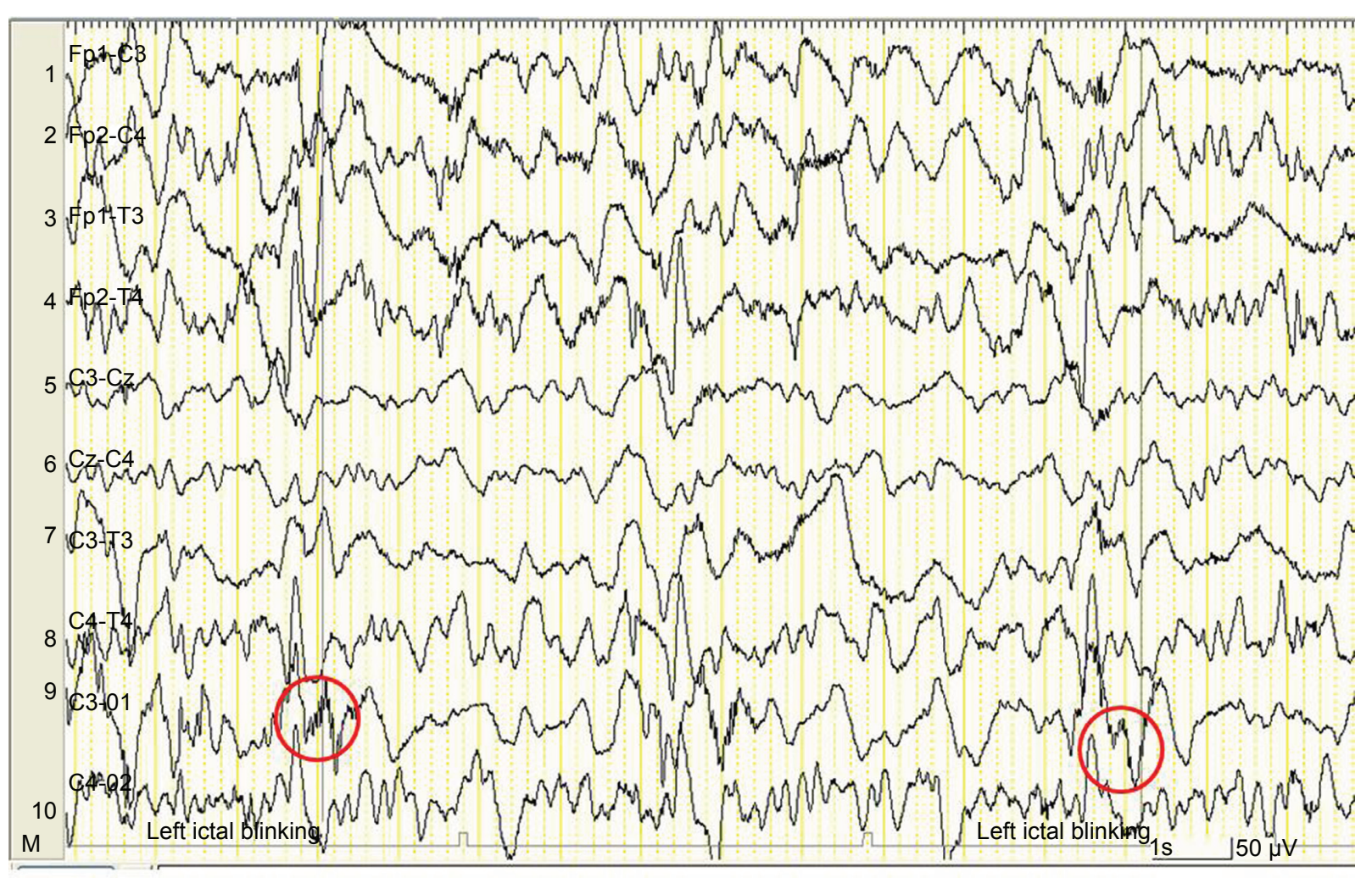

Figure I Specific electroencephalographic pattern of ictal blinking (red circles). 
possible association with other motor manifestations; so we suggest performing a meticulous video-EEG evaluation in all patients to correlate EEG findings with motor manifestations.

\section{Conclusion}

UIB is an ictal phenomenon of lateralization in partial seizures arising from different parts of the CNS. It is difficult to understand the specific EEG pattern of IB and its origin because in most cases it is not an isolated phenomenon, and it could be misdiagnosed for the association with other paroxysmal discharges. Future studies are needed to better understand the pathogenic mechanism at the basis of this phenomenon. Our findings showed that IB may be due to an epileptic discharge with an electroencephalographic pattern of a rapid ictal activity arising from occipital areas. If our hypothesis is confirmed by other cases worldwide, we could propose IB as a seizure type to be included in international classifications.

\section{Ethics}

All patients' parents signed a written informed consent to publish all the data of the children included in the present study. The study was approved by the Ethics Committee of the University of Catania, Italy. The study conformed to the ethical guidelines of the 1975 Declaration of Helsinki as revised in $2000 .^{15}$

\section{Acknowledgments}

We thank Mrs Stacy Taylor for her revision of our manuscript and editing of English grammar. The present study was partially funded by "Heinz Italia S.p.A." (grant number 626, July 9, 2015).

\section{Disclosure}

The authors report no conflicts of interest in this work.

\section{References}

1. Benbadis SR, Kotagal P, Klem GH. Unilateral blinking: a lateralizing sign in partial seizures. Neurology. 1996;46(1):45-48.

2. Bartholow R. Experimental investigations into the functions of the human brain. Am J Med Sci. 1874:305-313.

3. Kalss G, Leitinger M, Dobesberger J, Granbichler CA, Kuchukhidze G, Trinka E. Ictal unilateral eye blinking and contralateral blink inhibitionA video-EEG study and review of the literature. Epilepsy Behav Case Rep. 2013;1:161-165.

4. Henkel A, Winkler PA, Noachtar S. Ipsilateral blinking: a rare lateralizing seizure phenomenon in temporal lobe epilepsy. Epileptic Disord. 1999;1(3):195-197.

5. Falsaperla R, Perciavalle V, Pavone $P$, et al. Left eye blinking arising from the ictal ipsilateral occipital area. Clin EEG Neurosci. 2016;47(3): 243-246.

6. Pestana EM, Gupta A. Ipsilateral blinking seizures during left frontotemporal ictal pattern on scalp EEG. Epileptic Disord. 2007;9(4): 449-452.

7. Engel J Jr; International League Against Epilepsy (ILAE). A proposed diagnostic scheme for people with epileptic seizures and with epilepsy: report of the ILAE Task Force on Classification and Terminology. Epilepsia. 2001;42(6):796-803.

8. Berg AT, Berkovic SF, Brodie MJ, et al. Revised terminology and concepts for organization of seizures and epilepsies: report of the ILAE Commission on Classification and Terminology, 2005-2009. Epilepsia. 2010;51(4):676-685.

9. Lux AL, Osborne JP. A proposal for case definitions and outcome measures in studies of infantile spasms and West syndrome: consensus statement of the West Delphi group. Epilepsia. 2004;45(11): $1416-1428$.

10. Sindou M, Fobe JL, Berthier E, Vial C. Facial motor responses evoked by direct electrical stimulation of the trigeminal root. Localizing value for radiofrequency thermorhizotomy. Acta Neurochir (Wien). 1994; 128(1-4):57-67.

11. Aramideh M, Ongerboer de Visser BW. Brainstem reflexes: electrodiagnostic techniques, physiology, normative data, and clinical applications. Muscle Nerve. 2002;26(1):14-30.

12. Jadhav T, Bailey C, Maixner W, Harvey AS. Ictal unilateral blinking is an unreliable lateralizing sign in tuberous sclerosis complex. Epilepsy Res. 2016;125:58-61.

13. Mesiwala AH, Kuratani JD, Avellino AM, Roberts TS, Sotero MA, Ellenbogen RG. Focal motor seizures with secondary generalization arising in the cerebellum. Case report and review of the literature. J Neurosurg. 2002;97(1):190-196.

14. Specchio N, Trivisano M, Bernardi B, et al. Neonatal hemifacial spasm and fourth ventricle mass. Dev Med Child Neurol. 2012;54(8): 697-703.

15. Riis P. Perspectives on the Fifth Revision of the Declaration of Helsinki JAMA. 2000;284(23):3045-3046.
Neuropsychiatric Disease and Treatment

\section{Publish your work in this journal}

Neuropsychiatric Disease and Treatment is an international, peerreviewed journal of clinical therapeutics and pharmacology focusing on concise rapid reporting of clinical or pre-clinical studies on a range of neuropsychiatric and neurological disorders. This journal is indexed on PubMed Central, the 'PsycINFO' database and CAS,

\section{Dovepress}

and is the official journal of The International Neuropsychiatric Association (INA). The manuscript management system is completely online and includes a very quick and fair peer-review system, which is all easy to use. Visit http://www.dovepress.com/testimonials.php to read real quotes from published authors. 